child with persistent unexplained diarrhoea. Additional clues to the diagnosis are growth disturbance, electrolyte abnormalities, and social and psychological disturbance within the family.

\section{References}

1 Cooke WT. Laxative abuse. Clin Gastroenterol 1977;6:659-71.

2 Rogers D, Tripp J, Bentovim A, Robinson A, Berry D, Goulding R. Non-accidental poisoning; an extended syndrome of child abuse. Br Med J 1976;i:793-6.

${ }^{3}$ Fleisher D, Ament ME. Diarrhea, red diapers and child abuse. Clin Pediatr 1977;17:820-4.
${ }^{4}$ Devore CD, Ulshen MH, Cross RE. Phenolphthalein laxatives and factitious diarrhea. Clin Pediatr 1982;21:573-4.

${ }^{5}$ Kaspi T, Royds RB, Turner P. Qualitative determination of senna in urine. Lancet 1978;i:1162.

6 de Wolf FA, de Haas EJM, Verwelj M. A screening method for establishing laxative abuse. Clin Chem 1981;27:914-7.

Correspondence to Dr D G Gall, University of Calgary, Faculty of Medicine, Department of Pediatrics, 3330 Hospital Drive NW, Calgary, Alberta, Canada T2N $4 \mathrm{~N} 1$.

Received 30 July 1984

\title{
Diarrhoea due to Cryptosporidium in acute lymphoblastic leukaemia
}

\author{
I J LEWIS, C A HART, AND D BAXBY \\ Regional Unit of Paediatric Haematology and Oncology, Alder Hey Childen's Hospital, Liverpool, and \\ Department of Medical Microbiology, University of Liverpool
}

\begin{abstract}
SUMMARY We describe a case of recurring cryptosporidiosis during immunosuppressive treatment. The infection occurred after contact with an affected kitten and followed a less severe course than expected. After withdrawal of immunosuppressive treatment the infection resolved.
\end{abstract}

The protozoan parasite Cryptosporidium is increasingly recognised as a cause of enterocolitis in humans. In immunologically competent individuals, the commonest manifestation is explosive watery diarrhoea usually accompanied by vomiting, anorexia, cramping abdominal pains, and low grade fever. This is a self limiting illness lasting three to 14 days. ${ }^{1}$

Cryptosporidiosis in immunocompromised patients is characterised by intractable watery diarrhoea that is resistant to antimicrobial treatment and is associated with high mortality. ${ }^{1}$ We report a case of recurring cryptosporidiosis in a child on maintenance treatment for acute lymphoblastic leukaemia in whom the disease followed a less severe course than is usually recognised in immunocompromised subjects and which followed contact with an infected kitten.

\section{Case report}

A $5 \frac{1}{2}$ year old boy was diagnosed as having acute lymphoblastic leukaemia (non B, non T, c-ALL ${ }^{+v e}$ ) at the age of 4 years 9 months and was treated according to the Medical Research Council UKALL VIII A protocol. Nine months after diagnosis, while on maintenance treatment and in haematological remission, he presented with a brief history of anorexia, nausea, and loose stools. This coincided with similar symptoms in both parents and a sister. There were no abnormal clinical or laboratory findings and treatment was continued. The symptoms rapidly resolved in the rest of the family but continued for the subsequent four weeks in the patient. He became increasingly anorexic with intermittent vomiting, had between one and two profuse, watery, yellow stools per day, and suffered just over $10 \%$ weight loss.

Investigations six weeks after the onset of symptoms showed a haemoglobin concentration of 11.6 $\mathrm{g} / \mathrm{dl}$, total leucocyte count $3.5 \times 10^{9} / 1$, neutrophils $1.75 \times 10^{9} / 1$, lymphocytes $0.7 \times 10^{9} / 1$, monocytes $0.98 \times 10^{9} / 1$, eosinophils $0.07 \times 10^{9} / 1$, and platelets $384 \times 10^{9} / 1$. Bone marrow aspiration showed a marrow in remission with dyserythropoietic features. Urea, electrolytes, liver enzymes, serum proteins, and iron were normal. Serum folate was $1.4 \mathrm{mg} / \mathrm{l}$ (normal 3-12 mg/l), red cell folate $105 \mathrm{ng} / \mu \mathrm{l}$ (normal $200-700 \mathrm{ng} / \mu \mathrm{l}$ ). His one hour D-xylose absorption was $0.49 \mathrm{mmol} / 1(7.3 \mathrm{mg} / 100 \mathrm{ml}$ ) (normal 1.33 $\mathrm{mmol} / 1(20 \mathrm{mg} / 100 \mathrm{ml}))$. Bacterial and viral stool cultures were negative on a number of occasions, but oocysts of Cryptosporidium were detected on microscopic examination of stools using a safraninmethylene blue method. ${ }^{2} \mathrm{~A}$ jejunal biopsy showed noticeable cellular infiltrate but no abnormalities of the villi. Cryptosporidial trophozoites were found in 


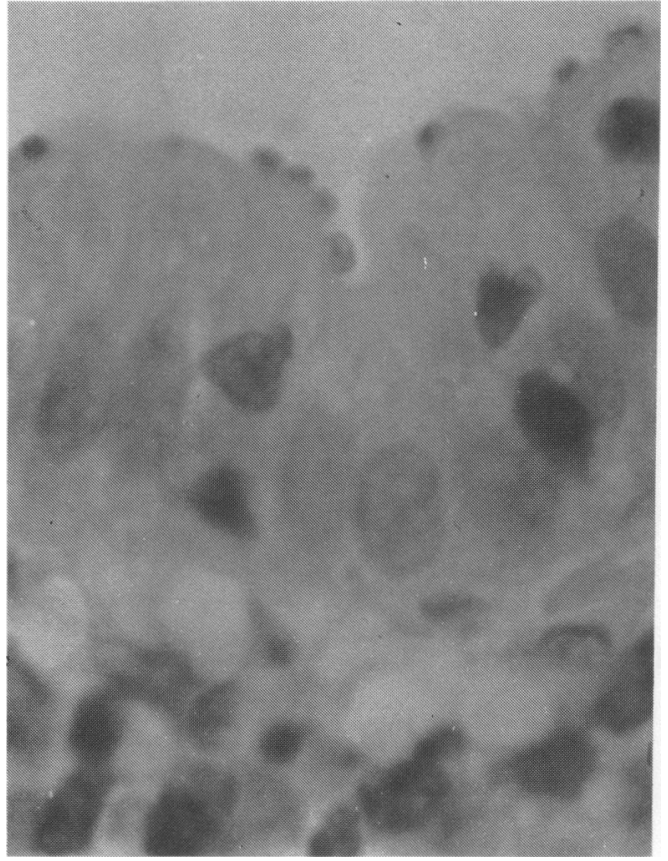

Figure Jejunal biopsy showing cryptosporidial trophozoites attached to mucosa ( $\times 1300)$.

Giemsa stained sections (Figure) and on electron microscopy.

Stool specimens from other family members were negative for Cryptosporidium oocysts. It was discovered, however, that the family had obtained a kitten two weeks before the onset of symptoms. The kitten had had occasional, loose stools and a sample obtained from her contained cryptosporidial oocysts.

Immunosuppressive drugs were stopped. The patient and cat were followed with thrice weekly stool examinations. The cat's stools were negative after the first sample. The patient continued to have symptoms of anorexia and loose stools for a further two weeks and was then started on nalidixic acid. His symptoms gradually resolved over the subsequent two weeks. The number of oocysts in his stools diminished and eventually cleared completely forty five days after diagnosis. After a repeat bone marrow aspiration he was restarted on maintenance treatment.

Six weeks after restarting treatment the patient's stools became slightly more watery and yellowish in appearance. Repeat examination again showed infection with Cryptosporidium. Further stool samples were obtained from the family cat and these were again positive. The patient's immunosuppressive drugs were withdrawn and he was restarted on nalidixic acid. His abnormal symptoms improved within a few days but he continued to excrete oocysts for a period of two and a half weeks. The cat was removed from the house and observed in an animal hospital. The cat's stools again became negative for Cryptosporidium after a two week period.

\section{Discussion}

The only previous patient reported with cryptosporidial infection during maintenance treatment for acute lymphoblastic leukaemia had severe and profuse watery diarrhoea with 25 to $40 \%$ daily weight loss. ${ }^{3}$ This is comparable with many of the reports of cryptosporidiosis in immune compromised patients, especially those with the acquired immune deficiency syndrome. Our patient followed a less severe and more chronic course than is usually recognised, although there have been occasional reports implicating Cryptosporidium in chronic diarrhoea. ${ }^{4}$

The first cases of human cryptosporidiosis were diagnosed by showing organisms in the duodenal or jejunal mucosa. In recent years a number of simple, rapid, sensitive, and cheap techniques have been developed for identifying cryptosporidial oocysts in stools, including the method used in this patient. ${ }^{2}$ The widespread adoption of these techniques would result in an increased incidence of diagnosis and greater understanding of the natural history of this infection.

Antimicrobial treatment for cryptosporidial infection has been singularly unsuccessful in previous reports, despite the use of a wide variety of potentially active drugs. ${ }^{5}$ Quinolones have not been previously used in cryptosporidiosis and although our patient improved after treatment with nalidixic acid, we felt that his improvement was probably associated with concurrent withdrawal of his immunosuppressive maintenance treatment.

It seems probable that our patient became infected as a result of contact with the family kitten. Transmission of Cryptosporidium from cat to man has rarely been described, ${ }^{6}$ although infection in man is well recognised as occurring as a result of contact with other mammals. ${ }^{1}$

It is noteworthy that this patient had a second episode of infection that coincided with the recurrence of oocysts in the cat's stools. Relapsing disease is recognised as occurring in calves and lambs but has not been well described in cats or humans.

It is, therefore, important that the identification of cryptosporidial diarrhoea in immune compromised patients should be accompanied by a careful 
search for possible contact with animals and, if necessary, removal of the offending animal from the home.

In view of the potentially serious effects of this infection, it is important to consider Cryptosporidium in the differential diagnosis of both acute and chronic diarrhoea in immune compromised subjects.

We thank Dr John Martin for allowing us to report his patient.

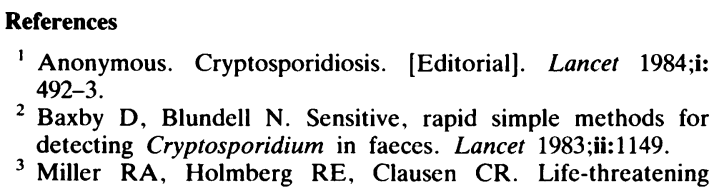

1 Anonymous. Cryptosporidiosis. [Editorial]. Lancet 1984;i: 492-3.

2 Baxby D, Blundell N. Sensitive, rapid simple methods for detecting Cryptosporidium in faeces. Lancet 1983;ii:1149.

${ }^{3}$ Miller RA, Holmberg RE, Clausen CR. Life-threatening

diarrhoea caused by Cryptosporidium in a child undergoing therapy for acute lymphocytic leukaemia. J Pediatr 1983; 103:256-9.

${ }^{4}$ Sloper KS, Dourmashkin RR, Bird RB, Slavin G, Webster ADB. Chronic malabsorption due to cryptosporidiosis in a child with immunoglobulin deficiency. Gut 1982;23:80-2.

5 Anonymous. Cryptosporidiosis: assessment of chemotherapy of males with acquired immunodeficiency syndrome (AIDS). [Editorial]. MMWR 1982;31:589-92.

${ }^{6}$ Koch KL, Shankey V, Weinstein GS, et al. Cryptosporidiosis in a patient with haemophilia, common variable hypogammaglobulinaemia and the acquired immunodeficiency syndrome. Ann Intern Med 1983;99:337-40.

Correspondence to Dr I Lewis, Regional Unit for Paediatric Haematology and Oncology, Alder Hey Children's Hospital, Liverpool L12 2AP.

Received 17 July 1984

\title{
Complications of diazoxide in the treatment of nesidioblastosis
}

\author{
M E McGRAW AND D A PRICE
}

Royal Manchester Children's Hospital

SUMMARY Two children with hypoglycaemia secondary to hyperinsulinaemia were treated with diazoxide. They suffered serious side effects of cardiac failure and truncal ataxia.

The usefulness of diazoxide, a non-diuretic benzothiadizine, in the management of severe hypoglycaemia is well documented. ${ }^{12}$ To date, reported side effects have been minimal and have not affected clinical management. We report two patients in whom severe side effects attributable to diazoxide have been encountered.

\section{Case reports}

Patient 1. This boy was born at 38 weeks' gestation after a normal pregnancy and delivery to a healthy 23 year old mother. His birthweight was $4.5 \mathrm{~kg}$; the birthweights of his two female siblings were $3.7 \mathrm{~kg}$ and $3.5 \mathrm{~kg}$. There was no maternal or family history of diabetes. The parents are both from Pakistan and are first cousins. On examination he was noted to have plethora, a cherubic appearance, length $55 \mathrm{~cm}$ (greater than the 90th centile), and head circumference $34 \mathrm{~cm}$ (50th centile); the remainder of the examination was unremarkable.

At 36 hours he was noticed to be irritable and then had a grand mal convulsion. His blood glucose concentration was $0.8 \mathrm{mmol} / \mathrm{l}(14.4 \mathrm{mg} / 100 \mathrm{ml})$ and he was therefore begun on dextrose infusion of 10 $\mathrm{mg} / \mathrm{kg} /$ minute and intravenous hydrocortisone. $\mathrm{He}$ remained hypoglycaemic until a glucagon infusion was started, after which his glucose concentration became normal. Insulin and $C$ peptide concentrations on two separate occasions confirmed hyperinsulinaemia (insulin 13 and $15 \mathrm{mU} / \mathrm{l}, \mathrm{C}$ peptide 1.6 and $1.8 \mathrm{pmol} / \mathrm{l}(4.8$ and $5.4 \mathrm{ng} / \mathrm{l})$, and glucose 1.0 $\mathrm{mmol} / \mathrm{l}(18 \mathrm{mg} / 100 \mathrm{ml})$ on both occasions. Treatment with oral diazoxide was initiated at $10 \mathrm{mg} / \mathrm{kg} /$ day increasing to a maximum of $22 \mathrm{mg} / \mathrm{kg} / \mathrm{day}$. All other treatment was gradually stopped and by day 15 he maintained a blood glucose concentration around $6 \mathrm{mmol} / \mathrm{l}(108.1 \mathrm{mg} / 100 \mathrm{ml})$ on full oral feeds and diazoxide alone.

On day 18 he became generally unwell with tachypnoea, tachycardia, and poor feeding. On examination he was not feverish, had a respiratory rate of 70 per minute, and a heart rate of 180 per minute with a hyperdynamic right ventricle and a loud systolic murmur heard in the pulmonary area. There was no hepatomegaly and his weight had remained stable. A chest radiograph showed increased lung vascularity and mild cardiomegaly, and an echocardiogram was normal apart from a possible patent ductus arteriosus. Treatment with digoxin and diuretics was begun but there was little cr no clinical improvement. 